\title{
EFEITO DO PERFIL DO DIRETOR ESCOLAR SOBRE A PROFICIÊNCIA DOS ALUNOS NO ESTADO DE MINAS GERAIS
}

\author{
Bianca Vieira Benedicto* \\ Evandro Camargos TeixeIra ${ }^{\dagger}$
}

\begin{abstract}
Resumo
Diversas pesquisas abordam os determinantes do rendimento escolar, no entanto pouco se discute na literatura quanto ao efeito do perfil do diretor sobre o aprendizado dos alunos. Nesse sentido, este trabalho utiliza o modelo hierárquico de regressão com o objetivo de avaliar o impacto que as características pessoais e gerenciais dos diretores apresentam sobre a proficiência dos alunos do terceiro ano do ensino médio do estado de Minas Gerais em 2017. Verifica-se que o perfil dos diretores se relaciona positivamente ao desempenho escolar, o que sugere maior investimento em programas de educação continuada voltados a eles.
\end{abstract}

Palavras-chave: perfil dos diretores, modelo hierárquico, rendimento escolar.

\begin{abstract}
Several studies address the determinants of school performance, however, little is discussed in the literature regarding the effect of the profile of principal on student learning. Thus, this paper employs the hierarchical regression model on two levels (multilevel) with the aim of assessing the impact of personal and managerial characteristics of principals on the proficiency of students in the 3rd year of high school in the state of Minas Gerais in 2017. It seems that the profile of the principals is positively related to school performance, which suggests further investment in continuing education programs for them.
\end{abstract}

Keywords: profiles of school headmasters, hierarchical model, school performance.

JEL classification: I20, I21.

DOI: http : / dx.doi .org/10.11606/1980-5330/ea132906

\footnotetext{
* Universidade de Aveiro. Doutoranda em Ciências Econômicas e Empresariais. E-mail: bianca_benedicto@ua.pt

${ }^{\dagger}$ Universidade Federal de Viçosa. Departamento de Economia. Professor Associado I. Email: evandro.teixeira@ufv.br
} 


\section{Introdução}

Desde a década de 1990, a política educacional brasileira teve como principal objetivo a universalização do ensino fundamental, além de ampliação das oportunidades (políticas inclusivas) e aumento do gasto público educacional. Apesar do maior volume de recursos empregado, ainda existem fortes questionamentos sobre a qualidade da educação brasileira. Nos testes internacionais de desempenho que visam a avaliar habilidades em leitura, matemática e ciências, o Brasil sempre se mantém nas últimas posições. Para se ter ideia, em 2015, foram avaliados aproximadamente 540 mil estudantes de 15 a 16 anos de 72 países. De acordo com o Relatório, o Brasil ocupava a 59a posição em leitura e a $66^{\mathrm{a}}$ em matemática, sendo que esta apresentava o estado mais alarmante: $70,25 \%$ dos alunos avaliados estavam abaixo do nível esperado (BRASIL. Ministério da Educação, INEP - Instituto Nacional de Estudos e Pesquisas Educacionais, Fundação Santillana 2016).

Além disso, percebe-se que as macrorregiões brasileiras apresentam disparidades substanciais em termos educacionais. Tratando-se notadamente do estado de Minas Gerais, tais desigualdades são evidentes. DOS SANTOS \& PALES (2012) afirmam que a região com o maior percentual de analfabetos no estado é a dos Vales do Jequitinhonha e do Mucuri, onde 26,57\% de sua população não sabe ler nem escrever, ao passo que o percentual de analfabetos nas regiões Sul, do Triângulo Mineiro e Central é bem menor - $14 \%$.

Diante desse quadro, DE ANDRADE et al. (2004) destacam a preocupação crescente das autoridades governamentais em implementar políticas que promovam a melhoria dos indicadores educacionais em termos não apenas quantitativos, mas sobretudo qualitativos. Essas políticas podem ser justificadas pelos benefícios que o investimento em capital humano proporciona aos indivíduos e à sociedade como um todo.

Entre os benefícios da educação, DE AQUINO (2011) destaca o papel na determinação da renda futura do indivíduo e da melhora na qualidade da mão de obra, que segue acompanhada de aumentos de produtividade, o que ocasiona outro efeito importante: o crescimento e desenvolvimento econômico do país.

Uma questão frequentemente levantada nos estudos do contexto educacional se refere à qualidade da educação, representada pelo desempenho escolar. Algumas pesquisas determinam o desempenho dos alunos por meio das características pessoais, socioeconômicas e escolares, conforme salientam MACEDO (2004), BIONDI \& DE FELÍCIO (2007), MACHADO et al. (2008) e MIGUEL et al. (2012). O desempenho de um estudante, por exemplo, pode ser apresentado tendo em vista a escolaridade dos pais, renda familiar, infraestrutura das escolas, características da comunidade, entre outros fatores. Em meio a todas as características que influenciam o desempenho escolar, este trabalho se atenta para o papel exercido pelo diretor na formação dos estudantes.

Nesse sentido, o diretor é fundamental ao espaço escolar, uma vez que propicia os fatores necessários para que o aluno seja estimulado nos estudos. De acordo com LÜCK (2009), os diretores não só planejam as atividades escolares, mas também são responsáveis pelas condições de trabalho dos professores, de modo a garantir sua assiduidade e motivação.

Além disso, a ação do diretor depende das relações estabelecidas com a comunidade, os funcionários da escola e, ainda, com instâncias superiores, ou seja, o ensino extrapola a comunidade escolar (professor e aluno) e se apoia 
também na participação das famílias. Hierarquicamente, os diretores ocupam posição mediadora dentro das escolas. De acordo com LIMA (1993), essa relação se estabelece de modo que os diretores podem comunicar aos pais muitas das medidas da instituição, assim como aos órgãos normativos as ações dos professores. Esse papel intermediador contribui substancialmente para o sistema educacional. Adicionalmente, LÜCK (2009) evidencia a importância da troca de informações entre os diretores com outras escolas que tenham os mesmos interesses. A troca de experiências pode provocar mudanças essenciais no interior da instituição. A autora sugere a incorporação de redes colaborativas para que haja essa troca de experiência entre os gestores, com o intuito de facilitar a complexa tarefa de gerir uma escola.

Para além da experiência, outro fator que favorece a produção de conhecimento é a escolaridade dos envolvidos no processo educacional. Alguns estudos se dedicam em explicar o diferencial de notas dos alunos a partir da escolaridade dos docentes. Apesar da significância da formação do professor, MENEZES FILHO et al. (2009) constatam que o nível de escolaridade do diretor também é importante para a qualidade do ensino.

Logo, tendo em vista a relevância do diretor no âmbito escolar, o objetivo deste artigo é analisar como o perfil do diretor escolar e o modo como este gere o processo educativo impactam na proficiência dos alunos no estado de Minas Gerais. A literatura concernente ao tema é extremamente escassa, particularmente no Brasil, como será apresentado na próxima seção. Apesar da referida escassez de trabalhos, estudos desse caráter são imprescindíveis, sobretudo porque permitem a implementação de políticas de melhoria educacional, ainda mais no caso do estado de Minas Gerais, onde as desigualdades educacionais são tão elevadas, como já ressaltado. Além disso, este trabalho se diferencia dos demais ao considerar um sistema organizado hierarquicamente, ou seja, admite-se que haja grupos de alunos que constituem uma turma e grupos de turmas que compõem uma escola; isto é, identificam-se dois níveis de hierarquia: alunos e escolas, de modo que os resultados encontrados são mais precisos e consistentes.

Seguindo esta introdução, há uma breve revisão da literatura sobre o tema, com o intuito de caracterizar o perfil dos diretores e suas atividades na unidade escolar. Descrevem-se, posteriormente, os aspectos metodológicos e o banco de dados utilizado, apresentando as variáveis que o compõem. Por fim, serão apresentados os resultados e as principais conclusões do trabalho.

\section{Evidências Empíricas Acerca do Efeito das Características dos Diretores sobre a Proficiência Escolar}

Já é amplamente reconhecido que a qualidade da educação está associada à competência dos educadores. Porém, a contínua busca pela qualidade educacional também se fundamenta nas competências dos diretores escolares. Nesse sentido, LÜCK (2009) suscita questões acerca do papel do diretor e da organização do trabalho escolar como fundamentais no processo educativo. Segundo a autora, o diretor equilibra as diferentes áreas de ação da escola e a interação entre as pessoas em torno de um ideário educacional comum.

Aos gestores compete também a construção da cultura escolar. O profissional deve ser guiado, segundo LÜCK (2009), pelos objetivos socioeconômicos com foco no desenvolvimento do aluno, para que não ocorram ações centradas 
em interesses pessoais, contrariando os propósitos educacionais. Tais líderes devem, portanto, inspirar valores mais amplos, cuja realização promova o ganho geral.

À vista disso, PEREDA et al. (2019) destacam que a gestão dos diretores escolares pode impactar o desempenho dos alunos de várias formas. Dentre estas, sabe-se que a assiduidade e a estabilidade dos gestores facilitam a realização das tarefas escolares e, consequentemente, contribuem para o desempenho dos alunos, uma vez que a manutenção das estratégias e objetivos pretendidos incrementa os resultados educacionais alcançados.

Outra característica que pode influenciar a proficiência dos alunos é a maior facilidade de obtenção de recursos por parte dos diretores, seja de fontes públicas, doações ou de resultado de campanhas diversas. Desse modo, o diretor escolar pode assumir a responsabilidade de tanto captar como gerir de maneira eficiente os recursos financeiros.

Nesse contexto, LÜCK (2009) afirma que o recurso adquirido pode ser utilizado para aquisição de material permanente, manutenção e conservação de pequenos reparos da unidade escolar, capacitação e aperfeiçoamento de profissionais da educação, desenvolvimento de atividades educacionais, entre outras finalidades. Assim, a gestão eficiente dos recursos escolares é importante, dado que uma boa infraestrutura influencia positivamente o desempenho escolar.

Em conformidade com LÜCK (2009), DOBBIE \& FRYER JUNIOR (2013) avaliaram as características gerenciais mais relevantes que explicam o rendimento dos alunos nas escolas públicas de Nova York, e observaram que as melhores escolas forneciam mais feedbacks para os professores. Adicionalmente, o estudo comprovou que o maior engajamento dos pais é efetivo para a evolução no aprendizado, sendo importante que as escolas tenham mais reuniões para tratar do desempenho e comportamento dos alunos.

Estudando o caso das escolas norte-americanas, os trabalhos de EBERTS \& STONE (1988) e de BÉTEILLE et al. (2012), além de denotarem impacto positivo da experiência do diretor sobre a proficiência dos alunos, se destacam por trazerem outros resultados distintos. No primeiro caso, os autores evidenciam que a falta de consenso entre diretores e professores, e a gestão escolar realizada de forma excessivamente coercitiva resulta em efeitos negativos sobre a performance dos alunos. Por sua vez, BÉTEILLE et al. (2012) chamam atenção para outra relação interessante. Os autores demonstram que a saída do diretor está associada com maior rotatividade dos professores, o que pode diminuir o desempenho dos alunos.

Nesse sentido, utilizando dados longitudinais dos diretores, GRISSOM et al. (2013) demonstraram que o tempo gasto em áreas específicas da liderança, como treinamento e avaliação, está associado com desempenho mais elevado em matemática. Com métodos experimentais, FRYER JUNIOR (2014) destacou outro aspecto: na média, a adoção de cinco práticas gerenciais em escolas com baixa performance nos Estados Unidos eleva de forma significativa o desempenho dos alunos em matemática.

Já COELLI \& GREEN (2012) utilizaram o desempenho dos alunos em testes longitudinais, incluindo efeitos fixos dos alunos, diretores e escolas. O estudo analisou a variância da eficácia do diretor, comparando períodos em que a escola o substitui ou não. $\mathrm{O}$ artigo evidenciou que o fato de uma escola ter um diretor com eficácia de 1 desvio-padrão acima da média relaciona-se com o desempenho dos alunos de aproximadamente 0,05 desvios-padrões acima 
da média. Por sua vez, BLOOM et al. (2015) analisaram a qualidade da gestão escolar em 1.800 escolas de oito países, incluindo o Brasil. Os autores verificaram que a qualidade na gestão escolar é correlacionada positivamente com elevada magnitude com a performance dos alunos, sendo tal efeito superior ao tamanho da classe, da competência ou qualidade dos professores.

Tratando-se das características pessoais dos diretores e estudando o Brasil, PEREDA et al. (2019) revelam que o nível de escolaridade e experiência com educação de modo geral podem estar relacionados ao rendimento escolar dos alunos. Além disso, há aspectos relevantes alusivos à gestão, como ter habilidades gerenciais, liderança, alcance de metas, influência sobre funcionários e alunos por meio de suas motivações, entre outras.

Nesse contexto, nota-se que o estudo das competências e atribuições para o cargo de diretor escolar é imprescindível, uma vez que o conceito de desempenho se associa intimamente ao conceito de competências. Segundo CATUNDA (2007), os encargos dos gestores escolares são considerados decisivos para o êxito das escolas e, consequentemente, para a melhoria dos serviços educacionais do país. Diante disso, essa concepção se tornou importante objeto de análise.

Diversas são as organizações que se dedicam ao estudo das competências atribuídas às diferentes ocupações no mundo. No Brasil, o Ministério do Trabalho mantém a classificação brasileira de ocupações (CBO) e define as competências para o cargo de diretor da seguinte forma: "Planejam e avaliam atividades educacionais; coordenam atividades administrativas e pedagógicas; gerenciam recursos financeiros; participam do planejamento estratégico da instituição e interagem com a comunidade e com o setor público (Ministério do Trabalho, 2002, não paginado)."

De modo semelhante, o ONET - Occupacional Information Network (2017) é um banco de dados on-line dos Estados Unidos que contém centenas de definições profissionais, entre elas a de diretor escolar. De acordo com essa fonte de informação, o diretor de escola primária e secundária deve possuir uma série de conhecimentos e habilidades.

No que se refere aos conhecimentos mínimos exigidos, destacam-se quatro: inicialmente, é necessário que o profissional tenha o conhecimento de princípios e métodos para a concepção curricular e de formação. Destaca-se ainda o conhecimento de negócios e princípios de gestão envolvidos no planejamento estratégico, alocação de recursos e técnica de liderança. O terceiro tipo de conhecimento exigido concerne aos princípios e processos de prestação de serviços. Isso inclui avaliação de necessidades dos alunos e atendimento a padrões de qualidade. Por fim, ressalta-se a importância do conhecimento de equipamentos, políticas, procedimentos e estratégias relevantes para promover operações de segurança eficazes, de modo a garantir a proteção dos alunos e das instituições.

Em relação às habilidades, o ONET - Occupacional Information Network (2017) alega que o profissional deve discursar clara e fluentemente, ter pensamento dedutivo, indutivo e crítico, e, por fim, ter sensibilidade a problemas, de modo a visualizar em curta distância estratégias educacionais.

Embora alguns pontos já tenham sido discutidos acerca das atribuições e importância dos diretores escolares, a literatura brasileira ainda é escassa quando se trata da influência direta dos gestores sobre o desempenho dos alunos Para se ter uma ideia, além do estudo de PEREDA et al. (2019), somente mais três foram encontrados. 
O primeiro trabalho que versou a temática no país foi o de DE BARROS \& MENDONÇA (1998). Os autores utilizaram dados em painel por estado para o período de 1983-1993, com informações do Censo Escolar da Pesquisa Nacional por Amostra de Domicílios (PNAD) e do Sistema Nacional de Avaliação da Educação Básica (Saeb), correlacionando o desempenho dos alunos com diferentes formas de seleção dos diretores. Os autores verificaram efeito positivo, porém diminuto, da forma de seleção do diretor sobre o desempenho dos alunos.

Posteriormente, MARIONI et al. (2014) investigaram o impacto da gestão escolar na proficiência em português e matemática dos alunos de escolas públicas e privadas. Para isso, utilizaram microdados em painel do "Estudo Longitudinal da Geração Escolar 2005” (Geres) de 2005 a 2008 para avaliar diferentes efeitos dos diretores no desempenho dos alunos. Os autores encontraram evidências do efeito positivo da gestão escolar sobre a confiança dos professores nos diretores, da atenção do diretor às normas administrativas e do diretor que estimula atividades inovadoras.

MIRANDA \& PAZELLO (2014) analisaram o impacto da rotatividade dos diretores de escolas públicas no desempenho dos alunos, utilizando informações da Prova Brasil entre 2005 e 2011. Como instrumento que representa a rotatividade dos diretores, dado o objetivo de controle da endogeneidade, utilizou-se a descontinuidade política nas eleições para prefeito. Como resultado, os autores verificaram que a troca do diretor diminui o desempenho dos alunos em até 11,06 pontos na escala Saeb.

Portanto evidencia-se que, além de pouco explorado, o tema ocorre de forma direcionada às questões gerais. As abordagens relativas ao desempenho escolar não consideram os gestores como determinantes da proficiência. Assim, o presente estudo não somente visa preencher uma lacuna importante no desenvolvimento da discussão científica, como também faz uma abordagem inédita na literatura ao contemplar as características pessoais e gerenciais dos diretores como determinantes do aprendizado dos alunos. Além disso, o método utilizado, a ser descrito na próxima seção, se mostra robusto mediante a literatura que tange o tema.

\section{Metodologia}

\subsection{Estratégia Econométrica}

Para investigar a associação entre o perfil do diretor e o rendimento escolar alcançado pelos estudantes, este trabalho utiliza o modelo de regressão hierárquico $^{1}$, ou modelo multinível. Segundo BARBOSA \& FERNANDES (2000), o modelo é construído com o intuito de respeitar a estrutura de agrupamento dos dados. Assim, levam-se em consideração diferentes níveis na variabilidade dos dados.

De acordo com BARBOSA \& FERNANDES (2000), quando se utiliza o modelo de regressão clássica, o pesquisador deve escolher a que nível deseja trabalhar - macro ou micro. Se o analista opta por trabalhar com o nível macro, a variabilidade intraescola poderá ser perdida. Por outro lado, se o modelo estiver a nível micro, será necessário que as variáveis explicativas referentes

\footnotetext{
${ }^{1} \mathrm{O}$ software estatístico utilizado na estimação do modelo econométrico foi o Stata versão 14.0.
} 
à escola sejam desmembradas para a unidade micro, podendo levar a conclusões errôneas.

Já o modelo multinível permite a utilização simultânea de dois níveis e produz estimativas eficientes. SHIRASU (2014) alega que alunos de uma mesma escola são mais semelhantes entre si do que alunos de escolas diferentes, devido à infraestrutura, aos mesmos professores e até a questões socioeconômicas. Quando os alunos são tratados de modo independente dos demais, há violação da hipótese de que os termos de erro são independentes e identicamente distribuídos no modelo de regressão linear clássico, tornando imprópria a estimação por Mínimos Quadrados Ordinários (MQO).

Segundo BARBOSA \& FERNANDES (2000), quando se considera um modelo de regressão hierárquico, o intercepto e o coeficiente de inclinação são variáveis aleatórias, dependentes da influência do nível hierárquico mais elevado e variam de escola para escola. Diante disso, o trabalho utilizará o modelo multinível com estrutura em dois níveis: em que as unidades do primeiro nível - os alunos - são agrupadas conforme as unidades do segundo nível, no caso, o diretor.

Sabe-se que os modelos de regressão multinível descrevem a relação entre as variáveis explicativas, que são representadas por $x$, e a variável dependente, no caso $y$, corresponde à proficiência média em língua portuguesa e matemática. Assim, dado que $x$ representa as variáveis explicativas a nível individual e $w$ as variáveis a nível agregado, a especificação do modelo será dada pelas Equações (1), (2) e (3). Considera-se uma amostra aleatória de dados coletada a partir de uma estrutura em dois níveis, em que o primeiro nível (alunos) é agrupado em unidades do segundo nível (diretor). Além disso, cada unidade de aluno é representada pelo índice $i$, e cada característica do diretor pelo índice $j$, como se pode verificar:

$$
\begin{aligned}
& Y_{i j}=\beta_{0 j}+\beta_{1 j} x_{i j}+e_{i j} \\
& \beta_{0 j}=y_{00}+y_{01} w_{j}+u_{0 j} \\
& \beta_{1 j}=y_{10}+y_{11} w_{j}+u_{1 j}
\end{aligned}
$$

Em que $b_{0 j}$ é o intercepto geral do modelo e $b_{1 j}$ é o coeficiente de inclinação associado à variável $x$, que representa o impacto da variável explicativa no rendimento médio do aluno, ambas definidas como variáveis aleatórias. Além dos parâmetros fixos a serem estimados, sabe-se que $u_{0 j}$ é o efeito individual do diretor, ou seja, o componente de erro aleatório do segundo nível associado ao intercepto; já $u_{1 j}$ é o componente de erro aleatório do nível do diretor associado ao coeficiente de inclinação, ambos com distribuição normal com média zero e variância $s_{u 0}^{2}$ e $s_{u 1}^{2}$, respectivamente.

Substituindo (2) e (3) em (1), obtém-se a expressão:

$$
Y_{i j}=y_{00}+y_{10} x_{i j}+y_{01} w_{j}+y_{11} w_{j} x_{i j}+u_{1 j} x_{i j}+u_{0 j}+e_{i j}
$$

Dado o modelo exposto, os coeficientes apresentam a seguinte interpretação: $y_{i j}$ representa a proficiência média do $i$-ésimo aluno da $j$-ésima escola, 
portanto, dirigida pelo $j$-ésimo diretor; $e_{i j}$ é a componente de erro aleatório associado ao aluno, representando o resíduo da medida do rendimento do estudante que o modelo não explica. Considera-se o erro do nível do aluno independentemente dos erros do nível do diretor; $b_{01} w_{j}$ simula o impacto das variáveis explicativas do nível do diretor, $w$, no rendimento médio do aluno; $b_{11} w_{j} x_{i j}$ representa o termo de interação entre as duas variáveis explicativas (aluno e diretor).

A regressão estimada, portanto, é linear e inclui outras variáveis explicativas de nível um e também de nível dois, porém a estrutura é análoga à apresentado na Equação (4). O modelo multinível com mais variáveis explicativas permite a obtenção do impacto destas novas variáveis na proficiência dos alunos, bem como dos outros termos de interação, de modo a ampliar a capacidade de explicação da variável dependente, dado que há diminuição da variabilidade total alcançada pelo modelo.

Este trabalho utilizará os dados do Saeb/Prova Brasil para o ano de 2013 no estado de Minas Gerais. Estes se baseiam na aplicação de testes padronizados de língua portuguesa e matemática e questionários socioeconômicos de estudantes da terceira série ensino médio.

Diante disso, busca-se relacionar as variáveis explicativas com a variávelresposta desempenho escolar. As variáveis explicativas, apresentadas na $\mathrm{Ta}$ bela 1 , são medidas tanto a nível micro, como as características dos alunos, quanto a nível macro, que diz respeito atributos do diretor. A variável-resposta é designada por KREFT et al. (1998) como variável de contexto.

As variáveis explicativas a nível individual consideram características físicas e familiares dos alunos. ALVES \& ORTIGÃO (2005) apontam que os meninos apresentam maior chance de repetência do que as meninas, assim como os alunos negros têm maior probabilidade de repetência do que os brancos, mesmo entre alunos com maior poder aquisitivo. Diante de uma provável atuação de discriminação racial e de gênero nas escolas, criou-se uma dummy para etnia do estudante e outra para sexo.

ALVES \& ORTIGÃO (2005) afirmam ainda que conciliar estudos com trabalho é um dos fatores relacionados ao baixo desempenho escolar. Assim, o trabalho é um fator associado ao aumento do risco de repetência. Desse modo, incorporou-se uma variável a fim de captar o efeito do trabalho fora de casa sobre a proficiência do aluno. Diante das evidências, espera-se sinal negativo dessa variável.

Adicionalmente, NOGUEIRA et al. (2009) afirmam que as famílias interferem na educação dos estudantes, particularmente por meio do provimento de condições físicas e do envolvimento direto no processo educacional. Esses insumos são mensurados pelas características sociodemográficas das famílias, tais como educação e ocupação dos pais, renda, etc. Com o intuito de construir um indicador de nível socioeconômico dos alunos, criou-se uma variável para escolaridade dos pais. Esta, que abrange tanto a escolaridade da mãe quanto do pai.

Além disso, foi incluída uma variável que representa a frequência com que os pais dos alunos comparecem às reuniões. Essa inclusão se baseia no argumento de que o acompanhamento escolar do aluno contribui com o processo educacional e fornece maior suporte familiar.

Por fim, ROAZZI \& ALMEIDA (1988) afirmam que o insucesso escolar pode ser analisado por diversos prismas. Para os professores, o insucesso representa a falta de base, motivação dos profissionais ou, ainda, o mau funcio- 
Tabela 1: Descrição das variáveis explicativas e sinais esperados

\begin{tabular}{|c|c|c|c|c|}
\hline \multirow[b]{2}{*}{ Aluno } & \multirow{2}{*}{$\begin{array}{l}\text { Dummies } \\
\text { Assumem } \\
\text { Valor } 1\end{array}$} & \multirow{2}{*}{$\begin{array}{c}\text { Dummies } \\
\text { Assumem } \\
\text { Valor } 0\end{array}$} & \multicolumn{2}{|c|}{ Sinais Esperados } \\
\hline & & & $\begin{array}{c}\text { Língua } \\
\text { Portuguesa }\end{array}$ & Matemática \\
\hline Sexo & Masculino & Feminino & - & + \\
\hline Raça & $\begin{array}{l}\operatorname{Branco}(a) \text { ou ama- } \\
\operatorname{relo}(a)\end{array}$ & Pardo(a)/Preto(a)/Indíg & na & + \\
\hline $\begin{array}{l}\text { Frequência com que } \\
\text { os pais comparecem às } \\
\text { reuniões }\end{array}$ & $\begin{array}{l}\text { Sempre ou quase sem- } \\
\text { pre/De vez em quando }\end{array}$ & Nunca ou quase nunca & + & + \\
\hline Escolaridade da mãe & Possui ensino superior & $\begin{array}{l}\text { Nunca estudou ou es- } \\
\text { tudou até no máximo o } \\
\text { ensino médio }\end{array}$ & + & + \\
\hline Escolaridade do pai & Possui ensino superior & $\begin{array}{l}\text { Nunca estudou ou es- } \\
\text { tudou até no máximo o } \\
\text { ensino médio }\end{array}$ & + & + \\
\hline Abandono da escola & $\begin{array}{l}\text { Nunca abandonou a es- } \\
\text { cola }\end{array}$ & Já abandonou & + & + \\
\hline Reprovação & Nunca reprovou & Já reprovou & - & - \\
\hline Aluno trabalha & Trabalha & Não trabalha & - & - \\
\hline
\end{tabular}

Fonte: Elaborada pelos autores a partir dos dados do SAEB - Sistema de Avaliação da Educação Básica (2017).

namento das estruturas educativas e sociais. Outros trabalhos apresentam o problema em termos meramente individuais: alunos pouco dotados, desmotivados, com problemas ou carências afetivas e de ordens diversas. De modo geral, estes últimos estudos envolvem questões que não se resolvem nas escolas.

Algumas pesquisas destacam outra dificuldade nesse contexto. Alunos que já foram reprovados podem ser acometidos por sentimentos de incapacidade, baixa autoestima e fracasso generalizado, de modo a prejudicar seu rendimento escolar e, em alguns casos, levá-los a abandonar a escola. Considerando tais circunstâncias, as últimas variáveis incluídas a nível individual buscam captar o efeito do insucesso escolar na ótica das reprovações e abandono escolar sobre os resultados dos estudantes. Assim, o conjunto de variáveis denominadas abandono da escola e reprovação foram transformadas em um índice que busca identificar se o aluno já foi reprovado alguma vez. Para isso, utilizou-se uma técnica de análise multivariada designada Análise de Componentes Principais (ACP) $)^{2}$.

As variáveis incluídas a nível agregado têm a finalidade de captar o perfil dos diretores. De acordo com LÜCK (2009), a qualidade dos diretores tem efeito positivo sobre o desempenho dos alunos, de modo que aqueles com maior titulação e mais experiência corroboram para que ocorra desempenho escolar mais elevado. Diante disso, inclui-se uma variável que representa a escolaridade do diretor e outra que corresponde à experiência, tanto na área de educação quanto em direção.

\footnotetext{
${ }^{2}$ Segundo HONGYU et al. (2016), a ACP é uma técnica multivariada de modelagem da estrutura de covariância que consiste na determinação de uma transformação ortogonal das variáveis originais para um novo conjunto de variáveis não correlacionadas, que são obtidas em ordem decrescente de importância.
} 
Tabela 1: Descrição das variáveis explicativas e sinais esperados (continuação)

\begin{tabular}{|c|c|c|c|c|}
\hline \multirow[b]{2}{*}{ Escola } & \multirow{2}{*}{$\begin{array}{l}\text { Dummies } \\
\text { Assumem } \\
\text { Valor } 1\end{array}$} & \multirow{2}{*}{$\begin{array}{l}\text { Dummies } \\
\text { Assumem } \\
\text { Valor } 0\end{array}$} & \multicolumn{2}{|c|}{ Sinais Esperados } \\
\hline & & & $\begin{array}{c}\text { Língua } \\
\text { Portuguesa }\end{array}$ & Matemática \\
\hline $\begin{array}{l}\text { Escolaridade do dire- } \\
\text { tor }\end{array}$ & Com ensino superior & $\begin{array}{l}\text { Sem superior ou supe- } \\
\text { rior incompleto }\end{array}$ & + & + \\
\hline Sexo & Masculino & Feminino & + & + \\
\hline $\begin{array}{l}\text { Apoio de instâncias su- } \\
\text { periores }\end{array}$ & $\begin{array}{l}\text { Há apoio de instâncias } \\
\text { superiores }\end{array}$ & $\begin{array}{l}\text { Não há apoio de instân- } \\
\text { cias superiores }\end{array}$ & + & + \\
\hline Troca de informações & $\begin{array}{l}\text { Há troca de informa- } \\
\text { ções com diretores de } \\
\text { outras escolas }\end{array}$ & $\begin{array}{l}\text { Não há trocas de infor- } \\
\text { mações com diretores } \\
\text { de outras escolas }\end{array}$ & + & + \\
\hline Apoio da comunidade & $\begin{array}{l}\text { Tem apoio da comuni- } \\
\text { dade }\end{array}$ & $\begin{array}{l}\text { Não tem apoio da co- } \\
\text { munidade }\end{array}$ & + & + \\
\hline $\begin{array}{l}\text { Anos de trabalho com } \\
\text { educação }\end{array}$ & $\begin{array}{l}\text { Trabalha com educa- } \\
\text { ção há mais de seis } \\
\text { anos }\end{array}$ & $\begin{array}{l}\text { Trabalha com educa- } \\
\text { ção há menos de seis } \\
\text { anos }\end{array}$ & + & + \\
\hline $\begin{array}{l}\text { Anos exercendo fun- } \\
\text { ção de direção }\end{array}$ & $\begin{array}{l}\text { Exerce função de di- } \\
\text { reção há mais de seis } \\
\text { anos }\end{array}$ & $\begin{array}{l}\text { Exerce função de dire- } \\
\text { ção há menos de seis } \\
\text { anos }\end{array}$ & & \\
\hline $\begin{array}{l}\text { Anos de direção na } \\
\text { mesma escola }\end{array}$ & $\begin{array}{l}\text { É diretor da mesma es- } \\
\text { cola há mais de seis } \\
\text { anos }\end{array}$ & $\begin{array}{l}\text { É diretor da mesma es- } \\
\text { cola há menos de seis } \\
\text { anos }\end{array}$ & + & + \\
\hline $\begin{array}{l}\text { Rotatividade dos pro- } \\
\text { fessores }\end{array}$ & $\begin{array}{l}\text { Ao menos } 50 \% \text { dos pro- } \\
\text { fessores possuem vín- } \\
\text { culo estável na escola }\end{array}$ & $\begin{array}{l}\text { Menos de } 50 \% \text { dos pro- } \\
\text { fessores possuem vín- } \\
\text { culo estável na escola }\end{array}$ & + & + \\
\hline $\begin{array}{l}\text { Escolaridade do profes- } \\
\text { sor }\end{array}$ & Com ensino superior & Sem ensino superior & + & + \\
\hline $\begin{array}{l}\text { Anos exercendo a fun- } \\
\text { ção de professor }\end{array}$ & $\begin{array}{l}\text { Exerce função de pro- } \\
\text { fessor há mais de seis } \\
\text { anos }\end{array}$ & $\begin{array}{l}\text { Exerce função de pro- } \\
\text { fessor há menos de seis } \\
\text { anos }\end{array}$ & + & + \\
\hline $\begin{array}{l}\text { Desenvolvimento de } \\
\text { práticas pedagógicas }\end{array}$ & $\begin{array}{l}\text { Professor propõe com } \\
\text { frequência as seguin- } \\
\text { tes atividades: [1] De- } \\
\text { ver de casa; [2] De- } \\
\text { senvolvimento de ativi- } \\
\text { dades em grupo para } \\
\text { que os alunos busquem } \\
\text { soluções de problemas; } \\
\text { [3] Propõe situações de } \\
\text { aprendizagem que se- } \\
\text { jam familiares ou de in- } \\
\text { teresse dos alunos. }\end{array}$ & $\begin{array}{l}\text { Professor não propõe } \\
\text { ou raramente propõe } \\
\text { atividades }\end{array}$ & + & + \\
\hline
\end{tabular}

Fonte: Elaborada pelos autores a partir dos dados do SAEB - Sistema de Avaliação da Educação Básica (2017). 
Para captar o efeito da experiência, criou-se um índice por meio da referida modelagem ACP, contendo as seguintes variáveis: anos de trabalho com educação, anos na função de direção e anos na direção da mesma escola. A análise de componentes principais é apropriada, pois as variáveis sob investigação são da mesma natureza, transformando-se, assim, um conjunto de variáveis correlacionadas em um conjunto de variáveis não correlacionadas.

No tocante à formação dos gestores escolares, há uma necessidade e, ao mesmo tempo, um desafio para os sistemas de ensino. LÜCK (2009) alega que a formação básica dos dirigentes escolares não se apoia sobre esta área de atuação específica e, mesmo quando esses profissionais a possuem, a formação em cursos superiores tem caráter menos prático e mais teórico.

Além disso, LÜCK (2009) afirma que existe oferta insuficiente de oportunidades para formação inicial de gestores escolares, recaindo sobre os sistemas de ensino a tarefa e a responsabilidade de promover cursos de capacitação para preparação dos diretores, dada a importância da formação continuada como condição para acentuar o processo de profissionalização dos dirigentes.

Por fim, acredita-se que o movimento pelo aumento da competência da escola exige maior competência da gestão. Logo, criou-se a variável gestão a partir da ACP. O conjunto original de variáveis que definem a denominada gestão é: ter ou não apoio de instâncias superiores e da comunidade à gestão e, ainda, se há ou não troca de informações com diretores de outras escolas.

\subsection{Dados}

Os dados utilizados provêm do Saeb para o ano de 2017, contemplando alunos da terceira série do ensino médio de escolas públicas e particulares do estado de Minas Gerais. A escolha por alunos da terceira série do ensino médio se deve à possibilidade de utilização da variável que denota se o aluno trabalha

A análise exclusiva para o estado de Minas Gerais se justifica por sua pujança econômica e populacional. Minas Gerais apresenta a terceira maior participação no produto interno bruto (PIB) e é o segundo estado mais populoso do país. Além disso, como ressaltado por DOS SANTOS \& PALES (2012) nesse estudo, o estado possui elevadas desigualdades educacionais entre suas mesorregiões, representadas pelas discrepantes taxas de analfabetismo, o que torna este estudo ainda mais relevante.

\section{Resultados}

Esta seção tem como principal objetivo apresentar os resultados obtidos. Inicialmente, serão analisadas as estatísticas descritivas a fim de apresentar a amostra selecionada neste estudo. A Seção 4.2 analisará a relação entre o perfil do diretor escolar e a proficiência dos alunos em língua portuguesa e matemática.

\subsection{Análise Descritiva}

Os dados abrangem 977 alunos do $3^{\circ}$ ano do ensino médio para o ano de 2017, dos quais 551 são do sexo masculino e 426 do sexo feminino. Foram aplicados testes de proficiência em língua portuguesa e matemática, sendo estas as variáveis-resposta dos modelos. 
A Prova Brasil fornece a escala de desempenho de matemática e língua portuguesa. O nível mínimo analisado de desempenho dos alunos nas duas disciplinas é de 225 pontos. Já a pontuação máxima avaliada pela prova é de 425 pontos para matemática e 475 pontos para língua portuguesa.

A média na prova de matemática para a terceira série do ensino médio foi de 270,10 pontos, com desvio-padrão de 24,71, valor mais próximo da nota mínima obtida, demonstrando indício de assimetria para a direita na distribuição das notas, ou seja, maior frequência de notas abaixo da média. A distribuição da variável de proficiência em matemática pode ser observada na Figura 1, à direita. Já o histograma à esquerda representa os resultados para língua portuguesa, sendo a média de 267,23 pontos e desvio-padrão de 22,47.

As variáveis explicativas do modelo são associadas ao nível de aluno e escola e apresentadas na Tabela 2. Quanto às variáveis do aluno, há praticamente o mesmo número de homens e mulheres, como ressaltado anteriormente. Já para os diretores, há prevalência do sexo feminino no cargo, aproximadamente $68,13 \%$, enquanto, para o sexo masculino, o percentual é de $31,87 \%$.

Diversos são os trabalhos ${ }^{3}$ que confirmam a figura feminina como principal protagonista da gestão escolar em todos os níveis de ensino. Apesar do predomínio feminino nos cargos de educação, DE SOUZA (2009) alega que há tendência de crescimento da presença masculina à medida que se avança em direção ao ensino médio.

Em relação à variável que representa o trabalho fora do domicílio, notase que o percentual de alunos inseridos no mercado de trabalho é de $29,42 \%$. Estudo realizado por BEZERRA (2006) suscita questões acerca de tais estudantes. Segundo o autor, alunos que apenas frequentam a escola aprendem mais quando comparados aos que estudam e trabalham. Além disso, a diminuição de rendimento escolar cresce a cada hora adicional de trabalho exercido.

No que diz respeito ao abandono da escola durante o período de aulas, o percentual de alunos é de 7,27\%, valor abaixo daqueles que foram reprovados, aproximadamente $33,30 \%$ da amostra. Considerando que ambas as variáveis constituem o insucesso escolar, MIGUEL et al. (2012) constataram ampla influência deste não apenas sobre o desenvolvimento dos indivíduos, mas também em seus resultados escolares, de forma que o atraso escolar é considerado um handicap ${ }^{4}$ significativo.

Quanto à frequência de comparecimento dos pais dos alunos às reuniões, observou-se que $57,41 \%$ dos responsáveis participam. Quando se trata de reuniões do conselho das escolas, verifica-se que 90,72\% dos colégios não se reúnem ou simplesmente ainda não têm um conselho formado.

Quanto à escolaridade dos pais, aproximadamente $20,18 \%$ das mães dos alunos têm formação superior. Já os pais apresentaram percentagem um pouco menor: $8,77 \%$. Esta variável é importante, pois filhos de pais mais escolarizados tendem a apresentar melhores desempenhos nos exames de proficiência, conforme MENEZES FILHO et al. (2009).

Tratando-se da escolaridade dos diretores, observou-se que $97,23 \%$ possuíam curso superior. Analisaram-se também as modalidades de cursos de pós-graduação de mais elevada titulação. Evidenciou-se que 9,80\% dos diretores concluíram pelo menos uma especialização. Já para os professores,

\footnotetext{
${ }^{3}$ Mais detalhes em DE SOUZA (2009), ECKMAN (2004) e COLLARD (2001).

${ }^{4} \mathrm{O}$ termo indica incapacidade ou desvantagem.
} 
Figura 1: Distribuição das notas de língua portuguesa e matemática dos alunos da terceira série do ensino médio em 2017
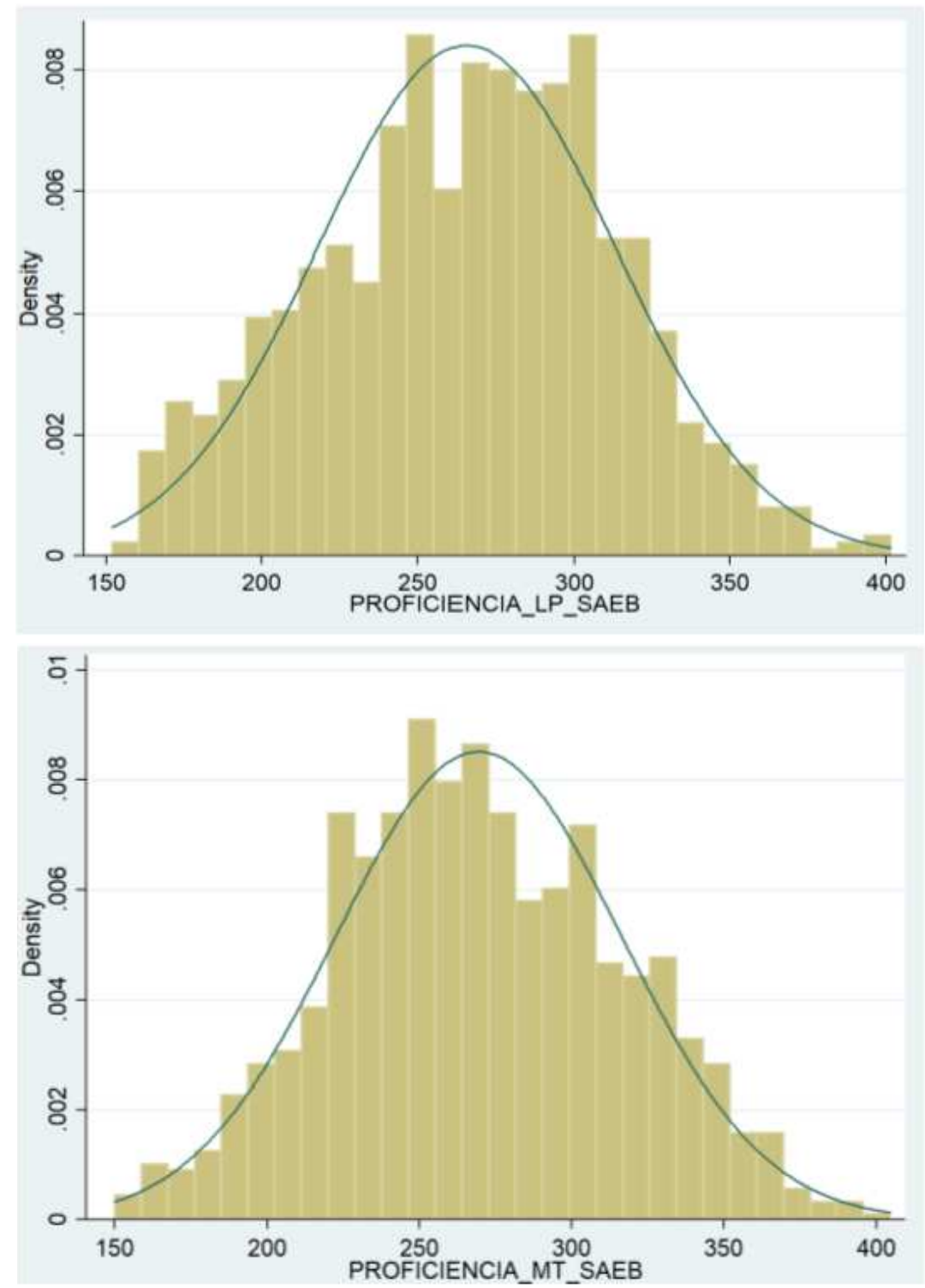

Fonte: Elaborada pelos autores a partir dos dados do SAEB - Sistema de Avaliação da Educação Básica (2017). 
constatou-se que $96,08 \%$ possuíam curso superior e 3,44\% concluíram o mestrado ou doutorado. Tais estatísticas são relevantes, pois a capacitação profissional é um meio indispensável para a implementação e o êxito das metas propostas.

A amostra revela ainda que $96,82 \%$ dos diretores trabalham há mais de seis anos com educação, contudo, considerando-se a experiência na área de direção, o percentual cai para $42,02 \%$. Adicionalmente, verifica-se que $30,99 \%$ trabalham há mais de seis anos na mesma escola e 19,67\% exercem outra atividade que contribui para sua renda pessoal, além da direção da escola. No que diz respeito ao professor, observa-se que $86,05 \%$ trabalham nessa atividade há mais de seis anos. No mais, ressalta-se que o trabalho abrange tanto escolas públicas quanto privadas, sendo $76 \%$ da amostra composta por escolas públicas.

\subsection{Resultados Econométricos}

A análise dos resultados econométricos denota o desempenho dos alunos em língua portuguesa e matemática condicionado à gestão escolar realizada pelo diretor. O primeiro modelo foi estimado em dois níveis e ajustado sem variáveis explicativas. O modelo somente de intercepto ou modelo nulo é útil porque proporciona uma estimativa da correlação intraescola $(\rho)$. O valor de $\rho$ pode ser calculado por meio da Equação (5):

$$
\rho=\frac{\sigma_{u}^{2}}{\sigma^{2}{ }_{u}+\sigma^{2}{ }_{u} e}
$$

em que $\sigma_{u}{ }^{2}$ é a variância dos resíduos $u$ do nível de diretor, e $\sigma \varepsilon^{2}$ é a variância dos resíduos e do nível de aluno.

O coeficiente de correlação demonstrado na Equação (5) pode variar de 0 a $100 \%$, sendo que valores próximos a zero significam maior homogeneidade entre as escolas, ou seja, o desempenho escolar dos alunos é independente da escola frequentada pelos alunos. Por outro lado, valores mais próximos de $100 \%$ demonstram maior dependência entre o rendimento escolar dos alunos e as escolas.

Assim, o modelo sem variáveis explicativas é essencial, pois por meio deste é possível obter o valor das variâncias em cada nível de hierarquia e, consequentemente, encontrar os valores de $\rho$. De acordo com RAUDENBUSH \& BRYK (2002), quanto maior o valor de $\rho$, mais elevada será a proporção da variância que é devida ao segundo nível. Desse modo, o cálculo do $\rho$ auxilia na escolha do modelo mais adequado.

Substituindo-se as variâncias encontradas na Tabela 3 na Equação (5), a correlação intraescola será de aproximadamente 0,4 . Assim, o valor da correlação intraescola indica a necessidade da utilização da modelagem multinível em vez de uma regressão tradicional, uma vez que as escolas não são homogêneas entre si, como exposto na Tabela 3.

Os resultados indicam valor de 264,63 para o intercepto no modelo de língua portuguesa e aproximadamente 268,24 para matemática. Isso pode ser interpretado como uma estimativa da média global dos alunos nos testes. A variância total para língua portuguesa foi de 62,96, sendo que 17,64 são de responsabilidade da variabilidade entre os diferentes diretores (escolas) e 45,32 
Tabela 2: Análise descritiva das características dos alunos e diretores

\begin{tabular}{|c|c|c|}
\hline Características do Aluno & Média & $\begin{array}{c}\text { Desvio- } \\
\text { padrão }\end{array}$ \\
\hline Frequência com que os pais comparecem às reuniões & $57,41 \%$ & 0,4847 \\
\hline Reuniões do conselho das escolas & $90,72 \%$ & 0,2902 \\
\hline Escolaridade dos pais & & \\
\hline Mãe com superior & $20,18 \%$ & 0,4015 \\
\hline Pai com superior & $8,77 \%$ & 0,2830 \\
\hline Aluno trabalha & $29,42 \%$ & 0,4559 \\
\hline Masculino & $43,60 \%$ & 0,4961 \\
\hline Branco & $28,16 \%$ & 0,4500 \\
\hline Características da Escola & Média & $\begin{array}{c}\text { Desvio- } \\
\text { padrão }\end{array}$ \\
\hline $\begin{array}{l}\text { Escolaridade do diretor } \\
\text { Superior } \\
\text { Pós-graduação }\end{array}$ & $\begin{array}{c}97,23 \% \\
9,8 \%\end{array}$ & $\begin{array}{l}0,2975 \\
0,2975\end{array}$ \\
\hline $\begin{array}{l}\text { Gestão } \\
\text { Apoio de instâncias superiores } \\
\text { Troca de informações } \\
\text { Apoio da comunidade }\end{array}$ & $\begin{array}{l}90,58 \% \\
94,03 \% \\
95,15 \%\end{array}$ & $\begin{array}{l}0,2920 \\
0,2368 \\
0,2147\end{array}$ \\
\hline $\begin{array}{l}\text { Experiência do diretor } \\
\text { Anos de trabalho com educação } \\
\text { Anos exercendo função de direção } \\
\text { Anos de direção na mesma escola }\end{array}$ & $\begin{array}{r}4,85 \% \\
66,38 \% \\
27,53 \%\end{array}$ & $\begin{array}{l}0,2148 \\
0,4724 \\
0,4466\end{array}$ \\
\hline $\begin{array}{l}\text { Escolas com } 50 \% \text { dos professores com vínculo estável (ro- } \\
\text { tatividade) }\end{array}$ & $26,23 \%$ & 0,4401 \\
\hline Escola pública & $76 \%$ & 0,1824 \\
\hline $\begin{array}{l}\text { Escolaridade do professor } \\
\text { Superior } \\
\text { Pós-graduação }\end{array}$ & $\begin{array}{r}96,07 \% \\
3,44 \%\end{array}$ & $\begin{array}{l}0,1943 \\
0,1824\end{array}$ \\
\hline Mais de seis anos exercendo a função de professor & $86,05 \%$ & 0,3468 \\
\hline Existência de biblioteca na escola & $2 \%$ & 0,0185 \\
\hline $\begin{array}{l}\text { Desenvolvimento de práticas pedagógicas } \\
\text { [1] Propõe dever de casa } \\
\text { [2] Desenvolvimento de atividades em grupo para } \\
\text { que os alunos busquem soluções de problemas } \\
\text { [3] Professor propõe situaçôes de aprendizagem } \\
\text { quejam familiares ou de interesse dos alunos }\end{array}$ & $\begin{array}{l}89,47 \% \\
91,15 \% \\
98,23 \%\end{array}$ & $\begin{array}{l}0,3082 \\
0,2852 \\
0,1324\end{array}$ \\
\hline
\end{tabular}

Fonte: Elaborada pelos autores a partir dos dados do SAEB - Sistema de Avaliação da Educação Básica (2017). 
Tabela 3: Resultado da estimação multinível sem variáveis explicativas para a terceira série do ensino médio em 2017

\begin{tabular}{|c|c|c|}
\hline & netros & $\begin{array}{c}\text { Estimativa } \\
\text { (Erro-padrão) }\end{array}$ \\
\hline \multicolumn{3}{|c|}{ Resultados para Língua Portuguesa } \\
\hline \multicolumn{3}{|l|}{ Fixos } \\
\hline & Intercepto & $\begin{array}{c}264,6316^{*} \\
(5,4934)\end{array}$ \\
\hline \multicolumn{3}{|l|}{ Aleatórios } \\
\hline & Nível 2: $\sigma_{u}{ }^{2}$ & $\begin{array}{c}17,6496^{*} \\
(4,3470)\end{array}$ \\
\hline & Nível 1: $\sigma \varepsilon^{2}$ & $\begin{array}{c}45,3258^{*} \\
(1,0201)\end{array}$ \\
\hline \multicolumn{3}{|c|}{ Resultados para Matemática } \\
\hline \multicolumn{3}{|l|}{ Fixos } \\
\hline & Intercepto & $\begin{array}{c}268,2408^{*} \\
(5,3658)\end{array}$ \\
\hline \multicolumn{3}{|l|}{ Aleatórios } \\
\hline & Nível 2: $\sigma_{u}{ }^{2}$ & $\begin{array}{c}17,2108^{*} \\
(4,2163)\end{array}$ \\
\hline & Nível 1: $\sigma \varepsilon^{2}$ & $\begin{array}{l}44,7743^{*} \\
(1,0076)\end{array}$ \\
\hline
\end{tabular}

daquela existente dentro das escolas, neste caso, devido aos alunos. Quando se trata dos resultados para matemática, a variabilidade no nível 2 aumenta para 17,21 . Por sua vez, no nível 1 , a variabilidade é de aproximadamente 44,77. Ademais, todos os efeitos foram significativos em 1\% de significância.

A Tabela 4 apresenta o modelo com a inserção das variáveis explicativas, tanto a nível individual (aluno) quanto a nível agregado (escola). A escolha desse modelo tem base na argumentação de que a variância do intercepto é mais bem explicada se comparada ao modelo com a inserção somente das variáveis a nível individual. Cabe ainda salientar que todas as variáveis apresentaram sinais esperados e significância estatística.

Observa-se que houve sensível diminuição na variância do modelo com variáveis explicativas comparado-se ao modelo nulo. No nível agregado, a variância de língua portuguesa foi de 17,64 para 9,71, enquanto para matemática foi de 17,21 para 12,13. Esse resultado pode ser explicado pelo fato de que a proporção de cada variável inserida é desigualmente distribuída entre as escolas. Por exemplo, existem escolas com diferentes proporções entre brancos e negros ou meninas e meninos. Assim, a inclusão das variáveis explicativas controla tais efeitos, de modo a ocasionar diminuição na variância do modelo multinível ajustado.

É possível verificar ainda que o desempenho escolar está intimamente relacionado à escola em que o aluno frequenta, ou seja, há dependência entre o primeiro e segundo nível do modelo. Quanto às variáveis de interesse, isto é, 
Tabela 4: Resultado do modelo multinível ajustado com variáveis explicativas para a terceira série do ensino médio em 2017

\begin{tabular}{|c|c|c|}
\hline Variáveis Explicativas & Língua Portuguesa & Matemática \\
\hline Nível Individual & Efeito & Efeito \\
\hline Intercepto & $\begin{array}{l}257,5978^{*} \\
(7,4679)\end{array}$ & $\begin{array}{l}256,6635^{*} \\
(7,4432)\end{array}$ \\
\hline Gênero do aluno (masculino) & $\begin{array}{l}0,9183^{* * *} \\
(3,6326)\end{array}$ & $\begin{array}{l}3,5544^{* *} \\
(3,5689)\end{array}$ \\
\hline $\begin{array}{l}\text { Etnia (outras versus } \\
\text { branco/amarelo) }\end{array}$ & $\begin{array}{l}2,3060^{* * *} \\
(3,9356)\end{array}$ & $\begin{array}{l}2,7470 \\
(3,8670)\end{array}$ \\
\hline $\begin{array}{l}\text { Frequência de comparecimento } \\
\text { dos pais às reuniões }\end{array}$ & $\begin{array}{l}2,4854^{* * *} \\
(3,5436)\end{array}$ & $\begin{array}{l}2,4040 \\
(3,4794)\end{array}$ \\
\hline $\begin{array}{l}\text { Escolaridade dos pais (mães/pais } \\
\text { ou responsáveis) }\end{array}$ & $\begin{array}{l}3,8078^{* * *} \\
(3,2344)\end{array}$ & $\begin{array}{l}1,4627 \\
(3,1756)\end{array}$ \\
\hline $\begin{array}{l}\text { Aluno nunca reprovou ou abando- } \\
\text { nou a escola }\end{array}$ & $\begin{array}{l}4,1142^{* *} \\
(3,0404)\end{array}$ & $\begin{array}{l}8,4173^{* *} \\
(2,9864)\end{array}$ \\
\hline Aluno trabalha & $\begin{array}{c}-2,4049^{*} \\
(3,9484)\end{array}$ & $\begin{array}{c}-2,8067^{*} \\
(3,8777)\end{array}$ \\
\hline Nível Agregado & Efeito & Efeito \\
\hline Escolaridade do diretor & $\begin{array}{l}5,9902^{*} \\
(7,8543)\end{array}$ & $\begin{array}{l}6,2571^{*} \\
(9,0363)\end{array}$ \\
\hline Gênero do diretor (masculino) & $\begin{array}{l}31,3219^{*} \\
(18,6999)\end{array}$ & $\begin{array}{l}0,0016^{*} \\
(0,1905)\end{array}$ \\
\hline Gestão & $\begin{array}{l}5,0216^{*} \\
(4,0671)\end{array}$ & $\begin{array}{l}3,7379^{*} \\
(3,2890)\end{array}$ \\
\hline $\begin{array}{l}\text { Experiência do diretor (área da } \\
\text { educação e direção) }\end{array}$ & $\begin{array}{l}4,4705^{*} \\
(3,5550)\end{array}$ & $\begin{array}{l}0,00003^{*} \\
(0,0002)\end{array}$ \\
\hline Rotatividade de professores & $\begin{array}{l}2.01 e-09^{*} \\
(1.68 e-08)\end{array}$ & $\begin{array}{l}0,0002^{*} \\
(0,2900)\end{array}$ \\
\hline Experiência do professor & $\begin{array}{l}0,00002^{*} \\
(0,0004)\end{array}$ & $\begin{array}{l}0,00001^{*} \\
(0,0003)\end{array}$ \\
\hline $\begin{array}{l}\text { Desenvolvimento de práticas pe- } \\
\text { dagógicas }\end{array}$ & $\begin{array}{l}6,4409^{*} \\
(4.2312)\end{array}$ & $\begin{array}{l}4,7828^{*} \\
(3,0491)\end{array}$ \\
\hline \multicolumn{3}{|l|}{ Efeito Aleatório Nível 2 (Agregado) $\sigma_{u}{ }^{2}$} \\
\hline Variância - intercepto & $\begin{array}{l}9,7114^{* *} \\
(4,0671)\end{array}$ & $\begin{array}{c}12,1264^{* *} \\
(8,5398)\end{array}$ \\
\hline \multicolumn{3}{|c|}{ Efeito Aleatório Nível 1 (Individual) $\sigma \varepsilon^{2}$} \\
\hline Variância de Rij & $\begin{array}{l}46,0612^{* *} \\
(1,2391)\end{array}$ & $\begin{array}{l}45,2664^{* *} \\
(1,2183)\end{array}$ \\
\hline
\end{tabular}

Fonte: Elaborada pelos autores.

${ }^{*}$ denota significância a $1 \%$; ${ }^{* *}$ denota significância a $5 \%$; ${ }^{* *}$ denota significância a $10 \%$. 
aquelas que caracterizam o perfil dos diretores, conclui-se que a cada novo patamar educacional alcançado pelos diretores, mais elevam-se as notas obtidas pelos estudantes. Logo constata-se que investimentos em escolaridade realizados pelos diretores tendem a gerar maior qualidade educacional. Contudo, apesar da complementariedade da formação inicial ser importante, LÜCK (2009) afirma que esta deve, sobretudo, acentuar o processo de profissionalização dos dirigentes, de forma a apoiar a evolução do seu desempenho na gestão escolar.

Em consenso, ABRUCIO (2010) afirma que a formação dos diretores contribui para a obtenção de melhores resultados escolares. O autor realizou uma pesquisa com o intuito de mensurar a qualidade do corpo de gestores, sendo um dos critérios utilizados da sua formação. De acordo com o autor, os gestores que alegaram não ter graduação que os preparassem para a função eram os que estavam à frente das piores escolas. Portanto nota-se que a capacitação dos gestores não se baseia em apenas ter ou não curso superior, mas sobretudo, que tenham se graduado em curso que os habilita para o exercício do cargo.

Além disso, salienta-se a significância da escolaridade do professor. ABRUCIO (2010) alega que a capacitação posterior é fator positivo. Entretanto, dada a insuficiência do curso de Pedagogia para a função diretiva, o autor ressalta a importância da capacitação direcionada à gestão. Apesar de tais indícios relacionados aos aspectos formativos na prática da gestão, o efeito da melhor formação ficou evidenciado, de modo que os diretores com maior escolaridade demonstram mais domínio sobre a profissão.

Os resultados evidenciam ainda que uma boa gestão envolve aspectos que vão além da formação dos diretores. Dentre eles, destaca-se a experiência adquirida pelos gestores na área da educação e direção. O efeito positivo da experiência sobre a proficiência é significativo, especialmente em língua portuguesa, em que o aumento de um ano na experiência elevou o desempenho dos alunos em 4,47 pontos. Ressalta-se nesse contexto que o tempo de permanência dos gestores nas escolas contribui para que seus atributos relacionados ao exercício da função se revertam no desenvolvimento da qualidade de ensino.

Dando continuidade à análise do perfil dos diretores, nota-se que a variável gestão também foi significativa, isto é, ter apoio de instâncias superiores e da comunidade e trocar informações com diretores de outras escolas impacta positivamente o desempenho dos alunos.

Cunha et. al. (2012) apresentaram resultados semelhantes. Segundo os autores, apesar da importância de oferecer condições adequadas de estudo - bibliotecas abastecidas, espaço para esporte, lazer e segurança - uma boa gestão se distingue pela participação da comunidade, por melhor controle dos processos e maior integração da equipe escolar. Percebe-se, portanto, que a interação entre professores, equipe pedagógica, funcionários, alunos, pais e comunidade não apenas faz parte das práticas de ensino, como ainda as forma e constrói.

No que diz respeito ao nível individual (aluno), uma variável que afetou o desempenho escolar dos estudantes negativamente foi o trabalho fora de casa. A cada aumento de uma unidade na escala de escore padrão de trabalho, o desempenho médio dos alunos diminui, especialmente para língua portuguesa.

BEZERRA (2006) já havia investigado a relação entre desempenho escolar e horas trabalhadas. Os resultados aqui apresentados estão em conformidade com o que foi evidenciado pelo autor, ou seja, horas a mais de trabalho dos 
alunos, sejam do sexo feminino ou masculino, contribuem para a queda do desempenho. O autor averiguou ainda que alunos que trabalham somente dentro do domicílio têm menor prejuízo quanto ao desempenho em relação àqueles que trabalham fora do domicílio. É possível atestar também que a carga horária de trabalho que demanda maior esforço físico dos estudantes implica em menos tempo dedicado aos estudos e, consequentemente, maior redução no desempenho escolar.

As demais variáveis explicaram a variância no desempenho, só que positivamente, exceto para o sexo masculino em língua portuguesa, que teve relação negativa com a proficiência dos alunos. No que concerne à etnia dos alunos, assim como esperado, em todas as séries os alunos brancos/amarelos têm desempenho mais satisfatório do que os demais. Além disso, estudantes com defasagem escolar apresentaram pior proficiência comparando-se aos alunos regularmente aprovados, o que já havia sido salientado anteriormente por ALVES \& ORTIGÃO (2005). No tocante ao desenvolvimento de práticas pedagógicas, a relação foi positiva. Desse modo, professores que desenvolvem determinadas atividades pedagógicas podem influenciar positivamente a proficiência dos alunos, as quais incluem: 1) propor dever de casa; 2) desenvolver atividades em grupo para que os alunos busquem soluções de problemas; 3 ) propor situações de aprendizagem que sejam familiares ou de interesse dos alunos. Outro fator importante verificado no âmbito escolar diz respeito à rotatividade dos professores. Escolas em que há maior vínculo estável de professores também refletem melhor desempenho estudantil.

Além disso, um ano a mais de escolaridade do diretor aumenta as notas em 5,99 pontos e 6,25 pontos para língua portuguesa e matemática, respectivamente (Tabela 4). Confirmando a importância da qualificação dos gestores, PAZETO (2000) aponta três recomendações de formação: a formação básica sólida em educação, qualificação científica e técnica em gestão de instituições e formação continuada, visando associar conhecimentos e experiências.

Quanto aos alunos do sexo masculino que apresentaram pior desempenho em língua portuguesa, segundo estudo de MENEZES FILHO et al. (2009), os homens têm, em média, notas maiores em matemática. Esse fato é decorrente, segundo o autor, de uma maior facilidade dos meninos para matérias de exatas e das meninas para matérias de línguas, o que corrobora os resultados encontrados. Apesar da distinção entre gêneros no rendimento escolar, SOARES \& TEIXEIRA (2006) afirmam que não há diferenciação entre as escolas quanto ao tipo de atendimento dado aos alunos do sexo masculino e feminino no sistema de educação.

Por fim, SOARES et al. (2004) denotam a importância da participação dos pais na vida escolar dos seus filhos. Segundo os autores, o envolvimento das famílias na rotina escolar favorece o desenvolvimento dos alunos, como constatado na Tabela 4. Nota-se que quanto maior a frequência de comparecimento dos pais às reuniões, mais elevadas são as proficiências escolares de seus filhos. Ademais, o comportamento da variável referente à escolaridade dos pais é absolutamente coerente com o resultado já verificado por BARBOSA \& FERNANDES (2000) - de fato, observa-se que há associação positiva com a proficiência. Alguns estudos utilizam a escolaridade dos pais para representar melhores condições socioeconômicas das famílias. Os resultados, neste caso, também são coerentes, de modo que alunos com menor nível socioeconômico apresentam menor proficiência. Essa argumentação é considerada em estudos adicionais, contudo não é objetivo deste estudo se ater a essa questão. 


\section{Considerações Finais}

Este estudo examinou a importância do perfil dos dirigentes educacionais na determinação do rendimento escolar dos alunos da terceira série do ensino médio no estado de Minas Gerais. Para tanto, foram utilizados os dados do (SAEB - Sistema de Avaliação da Educação Básica 2017).

À vista disso, a primeira conclusão deste artigo é a de que o desempenho escolar dos alunos sofre influência de variáveis de diferentes níveis hierárquicos. Nesse sentido, há uma contribuição com a pesquisa científica ao se considerar a dependência entre os estudantes de diferentes escolas.

Quanto aos resultados obtidos, se consideradas as características do diretor, verifica-se influência positiva das variáveis que denotam sua escolaridade, experiência e capacidade de gestão sobre o desempenho dos alunos mineiros. No que se refere à experiência, nota-se que, para ocorrer impacto positivo do diretor na vida escolar, é necessário, inicialmente, que este conheça a realidade da escola e ganhe experiência em gestão (administrativa, pessoal ou pedagógica) para, assim, implementar as devidas ações no sistema escolar.

Levando-se em consideração a escolaridade dos diretores, observou-se que os profissionais que têm formação superior influenciam de maneira mais significativa o desempenho dos alunos, quando comparados aos não graduados. Logo o fato de serem profissionais mais escolarizados revela uma característica pessoal importante para incrementar o desempenho dos alunos. Apesar da função de diretor muitas vezes ser mal remunerada ou de haver sobrecarga de trabalho, é de extrema importância que as escolas selecionem profissionais com elevada experiência na área e maior grau de instrução.

Análise similar pode ser realizada considerando-se a escolaridade dos professores, uma vez que a relação com a proficiência em ambas as disciplinas também foi positiva. Além disso, escolas cuja rotatividade dos professores é menor e, complementarmente, escolas que desenvolvem com frequência atividades pedagógicas, como propor situações de aprendizagem que sejam de interesse dos alunos, apresentam maiores proficiências.

Além disso, é possível perceber algumas condições existentes para uma boa gestão, como ter apoio de instâncias superiores e da comunidade. Nesse sentido, para fortalecer a base educacional, parece plausível que os diretores adotem práticas gerenciais que melhorem a comunicação dentro e fora das escolas, de maneira a estimular a troca de informações entre os gestores, especialmente entre profissionais mais experientes.

É necessário ater-se ainda ao fato de que o equilíbrio entre as questões pedagógicas e administrativas é imprescindível para uma boa gestão. Sugere-se, portanto, que os profissionais tenham domínio de ambas as áreas e que não haja priorização de uma delas, pois a negligência poderia prejudicar a gestão. À vista disso, é fundamental que haja cursos de capacitação voltados a dirigentes que enfatizem não somente a área da educação, mas também aspectos administrativos.

Por fim, apesar da significância das variáveis a nível agregado terem sido uma evolução nos estudos sobre educação, ainda há fatores que impactam o rendimento escolar e não são observáveis, como as habilidades inatas. Há, assim, a necessidade de mais estudos, que tenham como objetivo compreender os fatores que influenciam a proficiência, para que seja possível investir de forma concreta e direta no sistema escolar, dada sua grande importância para o desenvolvimento econômico de qualquer país. 


\section{Referências Bibliográficas}

ABRUCIO, F. L. (2010), 'Gestão escolar e qualidade da educação: um estudo sobre dez escolas paulistas', Estudos e Pesquisas Educacionais (n. 1), p. 241274.

ALVES, F. \& ORTIGÃO, I. (2005), 'A repetência escolar e os diferentes tipos de capital: um estudo a partir dos dados do Saeb - 2001', In: REUNIÃO ANUAL DA ANPED, 28 .

BARBOSA, M. E. F. \& FERNANDES, C. (2000), 'Modelo multinível: uma aplicação a dados de avaliação educacional', Est Aval Educ (n. 22), p. 135-154.

BEZERRA, M. E. G. (2006), O trabalho infantil afeta o desempenho escolar no Brasil?, PhD thesis, Tese (Doutorado em Economia Aplicada), Escola Superior de Agricultura "Luiz de Queiroz", Universidade de São Paulo, Piracicaba, 2006.

BIONDI, R. L. \& DE FELÍCIO, F. (2007), Atributos escolares e o desempenho dos estudantes: uma análise de painel dos dados do Saeb, Textos para discussão 28, INEP - Instituto Nacional de Estudos e Pesquisas Educacionais, MEC - Ministério da Educação, Brasília.

BLOOM, N., LEMOS, R., SADUN, R. \& VAN REENEN, J. (2015), 'Does management matter in schools', Econ J v. 125, p. 647-674.

BRASIL. Ministério da Educação, INEP - Instituto Nacional de Estudos e Pesquisas Educacionais, Fundação Santillana (2016), Brasil no PISA 2015: análises e reflexões sobre o desempenho dos estudantes brasileiros, Technical report, OECD - Organização para a Cooperação e Desenvolvimento Econômico, Brasília.

BÉTEILLE, T., KALOGRIDES, D. \& LOEB, S. (2012), 'Stepping stones: principal career paths and school outcomes', Soc Sci Res v. 41(n. 4), p. 904-919.

CATUNDA, A. C. (2007), Relação entre competência do diretor escolar e desempenho da escola: um estudo de dados da rede estadual de ensino da Bahia, Master's thesis, Universidade Federal da Bahia.

COELLI, M. \& GREEN, D. A. (2012), 'Leadership effects: school principals and student outcomes', Econ Educ Rev v. 31(n. 1), p. 92-109.

COLLARD, J. L. (2001), 'Leadership and gender an Australian perspective', Educ Manage Adm V. 29(n. 3), p. 343-355.

DE ANDRADE, A. M., FILGUEIRAS, C. A. C. \& SAlvATO, M. A. (2004), 'Educação - objetivo 2 - atingir o ensino básico universal, PUC-Minas (org.)', IDHS - Instituto de Desenvolvimento Humano Sustentável da PUC-Minas p. 102 p.

DE AQUINO, J. M. (2011), A ampliação da jornada escolar melhora o desempenho acadêmico dos estudantes? Uma avaliação do programa escola de tempo integral da rede, $\mathrm{PhD}$ thesis, Tese (Doutorado em Economia Aplicada), Escola Superior de Agricultura "Luiz de Queiroz", Universidade de São Paulo, Piracicaba, 2011. 
DE BARROS, R. P. \& MENDONÇA, R. (1998), O impacto de três inovações institucionais na educação brasileira, Texto para discussão n. 566, IPEA - Instituto de Pesquisa Econômica Aplicada, Rio de Janeiro.

DE SOUZA, A. R. (2009), 'Perfil da gestão da escola pública no Brasil: um estudo sobre os diretores escolares e sobre aspectos da gestão democrática', Revista Iberoamericana de Educación v. 49(n. 2), p. 1-12.

DOBBIE, W. \& FRYER JUNIOR, R. G. (2013), 'Getting beneath the veil of effective schools: evidence from New York City', Am Econ J Appl Econ v. 5(n. $4)$, p. $28-60$.

DOS SANTOS, G. R. \& PALES, R. C. (2012), 'Desenvolvimento regional e desigualdades sociais entre as macrorregiões de planejamento de Minas Gerais', In: ENCONTRO ANUAL DA ANPOCS, 36 .

EBERTS, R. W. \& STONE, J. A. (1988), 'Student achievement in public schools: do principals make a difference?', Econ Educ Rev v. 7(n. 3), p. 291-299.

ECKMAN, E. W. (2004), 'Similarities and differences in role conflict, role commitment, and job satisfaction for female and male high school principals', Educ Adm Q v. 40(n. 3), p. 366-387.

FRYER JUNIOR, R. G. (2014), 'Injecting charter school best practices into traditional public schools: evidence from field experiments', Q J Econ v. 129(n. 3), p. 1355-1407.

GRISSOM, J. A., LOEB, S. \& MASTER, B. (2013), 'Effective instructional time use for school leaders: longitudinal evidence from observations of principals', Educ Res v. 42(n. 8), p. 433-444.

HONGYU, K., SANDANIELO, V. L. M. \& DE OLIVEIRA JUNIOR, G. J. (2016), 'Análise de componentes principais: resumo teórico, aplicação e interpretação', Engineering and Science v. 5(n. 1), p. 83-90.

KREFT, I. G. G., \& DE LEEUW, J. (1998), Introducing multilevel modeling, 1st ed. edn, Sage, New York.

LIMA, E. C. A. S. (1993), 'A escola e seu diretor: algumas reflexões. O papel do diretor e a escola de $1^{\circ}$ grau', FDE - Fundação para o Desenvolvimento da Educação, Série Idéias (n. 12), p. 117-124.

LÜCK, H. (2009), Dimensões de gestão escolar e suas competências, 2nd ed. edn, Editora Positivo, Curitiba.

MACEDO, G. A. (2004), 'Fatores associados ao rendimento escolar de alunos da 5a série (2000) - uma abordagem do valor adicionado', In: ENCONTRO NACIONAL DE ESTUDOS POPULACIONAIS, 14 .

MACHADO, A. F., MORO, S., MARTINS, L. \& RIOS, J. (2008), 'Qualidade do ensino em matemática: determinantes do desempenho de alunos em escolas públicas estaduais mineiras', EconomiA v. 9(n. 1), p. 23-45.

MARIONI, L. S., FREGUGLIA, R. S. \& COSTA, A. B. M. (2014), Impacts of school management on educational development: a longitudinal analysis from the teacher's perspective, Associação Nacional dos Centros de Pósgraduação em Economia - ANPEC, Natal. 
MENEZES FILHO, N., NUÑEZ, D. F. \& RIBEIRO, F. P. (2009), 'Comparando as escolas paulistas com melhor e pior desempenho no Saresp e na prova Brasil', São Paulo Perspec v. 23(n. 1), p. 115-134.

MIGUEL, R. R., RIJO, D. \& LIMA, L. N. (2012), 'Fatores de risco para o insucesso escolar: a relevância das variáveis psicológicas e comportamentais do aluno', Revista Portuguesa de Pedagogia (n. 46-1), p. 127-143.

MIRANDA, J. G. \& PAZELLO, E. T. (2014), 'Rotatividade de diretores e desempenho da escola', In: ENCONTRO BRASILEIRO DE ECONOMETRIA, 36

NOGUEIRA, C. M. M., CUNHA, M. A. A., VIANA, M. J. B. \& RESENDE, T. F. (2009), 'A influência da família no desempenho escolar: estudo de dados da geração escolar 2005', Revista Contemporânea de Educação v. 4(n. 8), p. 384401.

ONET - Occupacional Information Network (2017), Education administrators, elementary and secondary school.

URL: Disponivel em: https://www.bls.gov/bls/occupation.htm

PAZETO, A. E. (2000), 'Participação: exigências para a qualificação do gestor e processo permanente de atualização', INEP - Instituto Nacional de Estudos e Pesquisas Educacionais, Em Aberto v. 17(n. 72), p. 163-166.

PEREDA, P., LUCCHESI, A., MENDES, K. \& BRESOLIN, A. (2019), 'Evaluating the impact of the selection process of principal in Brazilian public schools', Nova Econ v. 29(n. 2), p. 591-621.

RAUDENBUSH, S. W. \& BRYK, A. S. (2002), Hierarchical linear models: applications and data analysis methods, Vol. v. 1, 2nd ed. edn, Sage, New York.

ROAZZI, A. \& ALMEIDA, L. S. (1988), 'Insucesso escolar: insucesso do aluno ou insucesso do sistema escolar?', Revista Portuguesa de Educação v. 1(n. 2), p. 53-60.

SAEB - Sistema de Avaliação da Educação Básica (2017), Microdados do Instituto Nacional de Estudos e Pesquisas Educacionais - INEP.

URL: Disponivel em: http://inep.gov.br/microdados

SHIRASU, M. R. (2014), Determinantes da evasão e repetência escolar no Ceará, PhD thesis, Dissertação (Mestrado em Economia), Faculdade de Economia, Administração, Atuária e Contabilidade, Universidade Federal do Ceará, Fortaleza, 2014.

SOARES, M. R. Z., DE SOUZA, S. R. \& MARINHO, M. L. (2004), 'Envolvimento dos pais: incentivo à habilidade de estudo em crianças', Estud Psicol v. 21(n. 3), p. 253-260.

SOARES, T. M. \& TEIXEIRA, L. H. G. (2006), 'Efeito do perfil do diretor na gestão escolar sobre a proficiência do aluno', Estudos em Avaliação Educacional v. 17(n. 34), p. 155-186. 
